\title{
Postnatal development and LPS responsiveness of pulmonary adenosine receptor expression and of adenosine-metabolizing enzymes in mice
}

\author{
Juhani Metsola' ${ }^{1}$, Mikael Maksimow ${ }^{2}$, Marja Ojaniemi', Hanna Metsola ${ }^{3}$, Fumiko Marttila-Ichihara ${ }^{2}$, Reetta Vuolteenaho ${ }^{1,4}$, \\ Gennady G. Yegutkin², Marko Salmi², Mikko Hallman'and Sirpa Jalkanen²
}

BACKGROUND: Adenosine levels are regulated by ecto5'-nucleotidase/CD73 and adenosine deaminase (ADA). Adenosine regulates endothelial permeability and antiinflammatory responses via adenosine receptors. Here, the adenosine receptors and purine-converting enzymes were studied during postnatal development and inflammation.

METHODS: Newborn, 1-, 10-, 14-d-old and adult C57BL/6 mice were challenged intraperitoneally (i.p.) with lipopolysaccharide (LPS) for $6 \mathrm{~h}$. The inflammatory response was evaluated by histochemistry. Expression levels of adenosine receptors $(A 1, A 2 A, A 2 B$, and $A 3), C D 73$, and ADA were measured by quantitative reverse transcription polymerase chain reaction. A1 was studied by immunohistochemistry, and enzyme activities were analyzed by thin-layer chromatography.

RESULTS: LPS caused respiratory distress in newborns within $24 \mathrm{~h}$. LPS induced neutrophils at the basal stage and alveolar congestion. Low activity and expression of CD73 increased after birth. Expression of ADA after LPS increased 16-fold in adults and 2 -fold in newborns $(P<0.05)$. A1 expression was high in newborns and increased after LPS $(P<0.05)$. A1 was localized to endothelial membranes. A2A decreased after LPS in newborns and increased in adults $(P<0.05)$. The expression of $\mathrm{A} 3$ increased in newborns and adults after LPS.

CONCLUSION: Low pulmonary CD73 expression, LPS-induced suppression of A2A, LPS-induced increase of A1 expression, and severe respiratory distress were distinguishing responses in the newborns from those in the adults.

A denosine is a purine base, which is an integral component of DNA-RNA and has several additional functions. It has been shown to regulate vascular endothelial integrity. As a predominantly extracellular signaling molecule, adenosine has recently been implicated as an important mediator of pulmonary inflammation (1). Ecto-5' nucleotidase (CD73, EC 3.1.3.5) is a cell-surface enzyme, which produces extracellular adenosine from adenosine monophosphate (AMP) in the vasculature
$(2,3)$. Adenosine then binds to its receptors or is metabolized by adenosine deaminase (ADA, EC 3.5.4.4) or by adenosine kinase (AK) to inosine or AMP, respectively (2). CD73 increases and $\mathrm{ADA}$ decreases the adenosine levels. It has been shown that interferon- $\beta$ (IFN- $\beta$ ) enhances the activity of CD73 in mice and man, leading to an increase in adenosine levels in the vascular endothelium and a decrease in vascular leakage $(4,5)$.

The effects of adenosine can be anti- or proinflammatory, depending on its concentration and on the type of receptor being activated. There are four different receptors that transmit the effects of adenosine to intracellular compartments: A1, $\mathrm{A} 2 \mathrm{~A}, \mathrm{~A} 2 \mathrm{~B}$, and A3. A2AR and A2BR are Gs-type G-proteincoupled receptors (GPCRs), which increase the levels of intracellular cAMP, whereas A1R and A3R are Gi-type GPCRs. Activation of Gi GPCR leads to a decrease in intracellular cAMP levels (6).

Lipopolysaccharide (LPS), an integral part of the outer wall of Gram-negative bacteria, is capable of launching a proinflammatory response. Several lines of evidence suggest a role for adenosine receptors in modulating LPS-induced pulmonary inflammation $(7,8)$. Activation of A3R has been shown to reduce LPS toxicity in a murine model of lung inflammation by downregulating LPS-induced influx of polymorphonuclear cells to the lungs (9). In porcine monocytes, an adenosine analog, N-ethylcarboxyamidoadenosine, downregulates tumor necrosis factor (TNF)- $\alpha$ production and upregulates interleukin (IL)-8 production after LPS stimulation, the effect being mediated mainly by A2AR (10). LPS has also been implicated in the induction of A2AR expression in murine macrophages, this being primarily mediated by nuclear factor- $\kappa \mathrm{B}$ (11). Preclinical studies have shown that an A2AR agonist improves lung function after acute lung damage and that the timely activation of A2AR limits the inflammation (12).

There is growing evidence of the importance of the adenosine system in early postnatal life. Neonatal blood CD73 activity was reported to be higher than ADA activity favoring elevated adenosine levels (13). The ADA activity was shown to increase 
during postnatal development. Serum ADA levels in preterm infants affected by bronchopulmonary dysplasia were elevated in the early postnatal phase (14). The high levels of adenosine in the blood of neonates inhibited acute TNF- $\alpha$ response (15). Caffeine has been proposed to inhibit TNF- $\alpha$ production via antagonizing A1R (16). Caffeine treatment of preterm infants with apnea of prematurity has been shown to decrease the plasma levels of TNF- $\alpha$ and IL-6 (17).

Respiratory distress shortly after birth and in early infancy is a major cause of chronic morbidity in premature neonates. The inflammatory insult is either a primary cause of lung disease or a principal factor influencing its progression $(18,19)$. At term birth and thereafter, the airways are relatively resistant to endotoxins. In contrast, preterm infants may be susceptible to the consequences of LPS-induced inflammatory injury $(20,21)$. In addition, peritoneal infection and inflammation due to Gramnegative bacteria is associated with serious cardiorespiratory distress after preterm birth $(22,23)$. Endothelial function plays a crucial role in many inflammatory diseases in which vascular permeability is one of the main pathogenic factors (24-26). The mechanisms protecting against infections and generalized inflammation may also require defense functions that are confined to the vascular endothelium.

Newborns are susceptible to respiratory distress induced by sepsis often caused by Gram-negative bacteria from the intestinal tract. Since adenosine is known to be capable of modulating the pulmonary inflammation, we hypothesized that the factors supporting high adenosine levels during perinatal period would protect the mice from pulmonary inflammation and respiratory distress. Therefore, we studied the expression of adenosine producing, sensing, and metabolizing proteins in response to intraperitoneal (i.p.) LPS in different age groups of mice. Here, we show evidence that both basal expression levels and responsiveness of adenosine-metabolizing enzymes and adenosine receptors to LPS are age-dependent. We propose that the immaturity of the adenosine signaling system needs to be considered as a factor predisposing to vascular inflammatory injury in early life.

\section{RESULTS}

\section{Sensitivity to Endotoxin-Induced Respiratory Distress and Pulmonary Damage}

In i.p. LPS dose-response experiments, newborn mice were more susceptible to LPS toxicity when compared with older animals. The dose selected (0.5 $\mu \mathrm{g}$ LPS, serotype 0111:B4/g body wt.) caused no detectable symptoms in the adult animals (unpublished data) and resulted in no mortality and hardly any respiratory distress in 14 -d-old pups $(n=7)$. In contrast, $53 \%$ of the newborns ( $n=15$; age $<12 \mathrm{~h}$ when LPS was given) presented with gasping and skin color changes and died, indicating severe respiratory distress within $12-24 \mathrm{~h}$ after the LPS insult. The rest of the newborn pups presented with respiratory distress that was not fatal during the observation period of $24 \mathrm{~h}$. None of the placebo-injected pups $(n=8)$ developed respiratory distress.

As the animals became symptomatic within the first $12-24 \mathrm{~h}$ after the LPS injection, in the subsequent experiments, we sacrificed the mice $6 \mathrm{~h}$ after the LPS injection to investigate the early events.

Histological analyses of the lungs of newborn, 14-d-old and adult mice were carried out to study the effects of LPS. As expected, the structurally immature lungs of newborn mice revealed no true alveoli, whereas lungs from 14-d-old animals revealed alveolar saccules. The study had a power to detect only large differences in the inflammatory response. However, only a few trends in lung histology were evident, and they did not reach statistical significance (Table 1): Newborn mice tended to have more neutrophils at the basal stage than the older animals. Transmigration of neutrophils after the endotoxin challenge tended to increase neutrophil counts in 14-dold and adult animals, and alveolar congestion increased after the LPS insult especially in the younger age groups.

\section{The Ontogenic Changes in CD73 and ADA Activities}

There were no differences between treatment groups in CD73 activity levels, and therefore, we pooled control and LPS animals to study the ontogenic differences. The activity of CD73 in the lungs increased significantly with age (Figure 1a). In 10-d-old mice, CD73 activity was threefold higher than in the newborn mice $(P<0.05)$. To study whether the expression levels of CD73 parallel the changes in its activity, CD73 mRNA levels were measured in newborn, 14-d-old and adult mice. The expression levels of CD73 in the lungs were five- to sixfold higher in 14-d-old and adult mice than in newborn mice $(P<0.05)$ (Figure 2a). The expression of CD73 did not differ between 14-d-old and adult mice. Since ADA affects the serum levels of adenosine, its expression levels were measured as well. ADA activity in 10-d-old mice as compared to younger animals was twofold (Figure 1b). Basal expression levels of ADA revealed no detectable trends after birth, either (Figure $2 b$ ).

\section{The Ontogenic Changes in Adenosine Receptor Expression Levels}

The expression levels of A1R, A2AR, A2BR, and A3R in the lungs were measured in newborn, 14-d-old and adult mice. The expression levels of $\mathrm{A} 1 \mathrm{R}$ are shown in Figure 3a. The basal level was twofold higher in newborn than in 14-d-old and adult mice $(P<0.05)$. The pulmonary expression levels of $\mathrm{A} 2 \mathrm{AR}, \mathrm{A} 2 \mathrm{BR}$, and A3R did not show differences between age groups (Figure $3 \mathrm{~b}-\mathrm{d}$ ).

Table 1. Histological analysis of lungs

\begin{tabular}{lcccccc}
\hline & \multicolumn{2}{c}{$\begin{array}{c}\text { Neutrophil count per 5 } \\
\text { high-power fields (SD) }\end{array}$} & & \multicolumn{2}{c}{$\begin{array}{c}\text { Alveolar congestion } \\
\text { (SD) }\end{array}$} \\
\cline { 2 - 3 } \cline { 5 - 6 } Age & Sham & LPS & & Sham & LPS \\
\hline Newborn & $113.3(34.9)$ & $124.6(23.6)$ & & $1.7(0.8)$ & $2.4(1.1)$ \\
14-d-old & $78.3(30.3)$ & $141.8(45.1)$ & & $1.7(0.8)$ & $2.2(0.8)$ \\
Adult & $62(30.4)$ & $121.3(57.6)$ & & $1.3(0.8)$ & $1.7(0.6)$ \\
\hline
\end{tabular}

aAlveolar congestion was graded via a four-tiered system from two tissue sections: no congestion $=0$, congestion in $<25 \%$ of the field area $=1$, in $25-49 \%$ of the field area $=2$, in $50-74 \%$ of the field area $=3$, and in $75-100 \%$ of the field area $=4$.

LPS, lipopolysaccharide. 
a

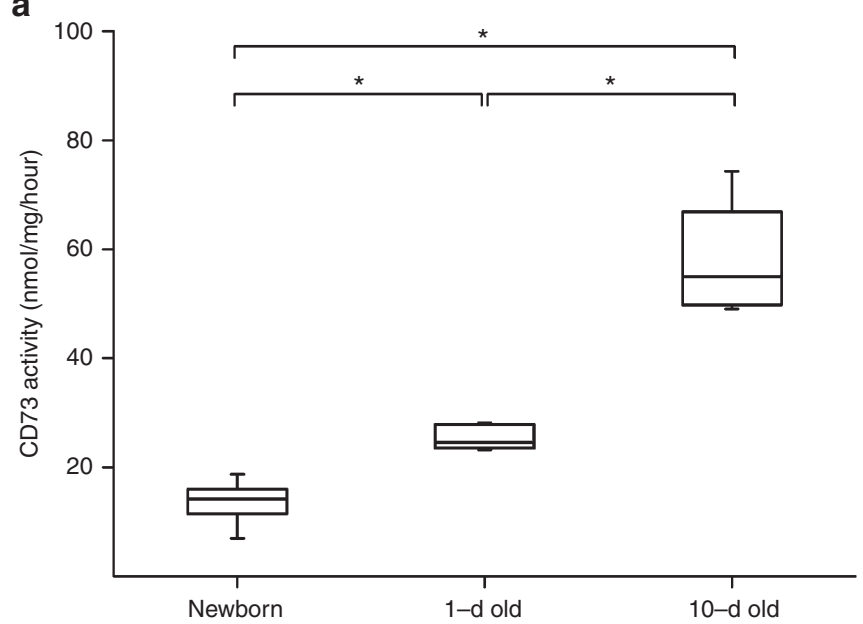

b

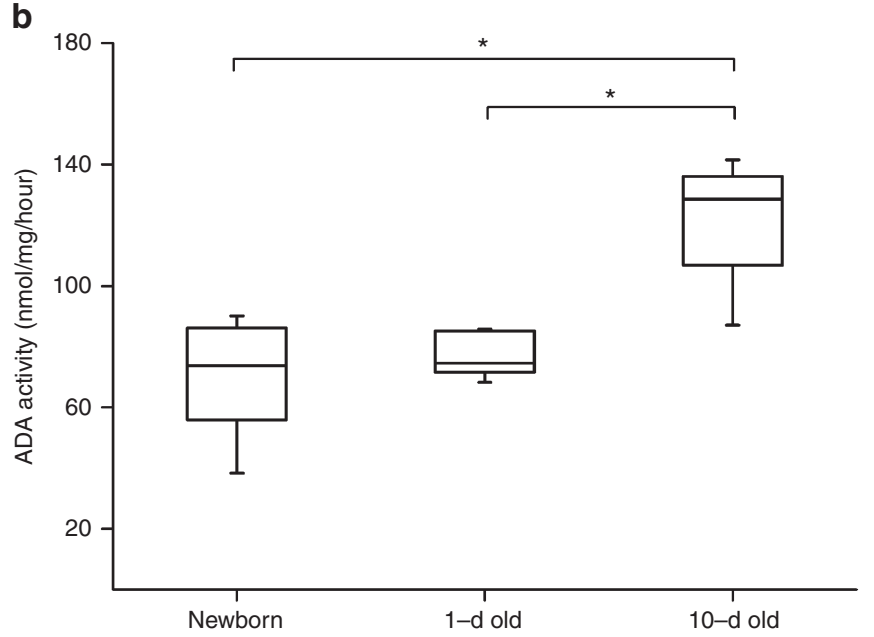

Figure 1. Enzyme activities of CD73 and adenosine deaminase (ADA) increase with age. Activity of CD73 (a) and ADA (b) in 0-d-old newborn $(n=6), 1-\mathrm{d}-(n=6)$, and 10-d-old $(n=4)$ animals. ${ }^{*} P<0.05$.

The Expression Levels and Activities of CD73 and ADA After LPS When the influence of i.p. LPS challenge on the expression levels of adenosine-metabolizing enzymes was studied, LPS did not alter the expression levels of CD73 in any age group (Figure 2). In contrast, the expression of ADA increased 2- (newborn, 14 -d-old) to 16 -fold (adult) after the LPS challenge $(P<0.05)$. After the LPS, the levels were eightfold higher in adult mice than in newborn and 14 -d-old mice $(P<0.05)$. There were no detectable increases in either CD73 or ADA activities as studied $6 \mathrm{~h}$ after the i.p. LPS injection (data not shown).

\section{The Expression Levels of Adenosine Receptors After LPS}

There was a twofold increase in the expression of A1R after LPS injection in newborn and 14-d-old mice compared with saline-injected animals $(P<0.05)$. Adult mice showed no increase of A1R expression after the LPS challenge (Figure 3a). In newborn mice, the expression of A2AR decreased 50\% $(P<0.05)$ after the LPS injection, whereas in 14 -d-old animals, there were no detectable changes in the expression levels after LPS. In adult mice, a sixfold increase in A2A receptor expression was detected after the LPS challenge $(P<0.05)$. Overall,
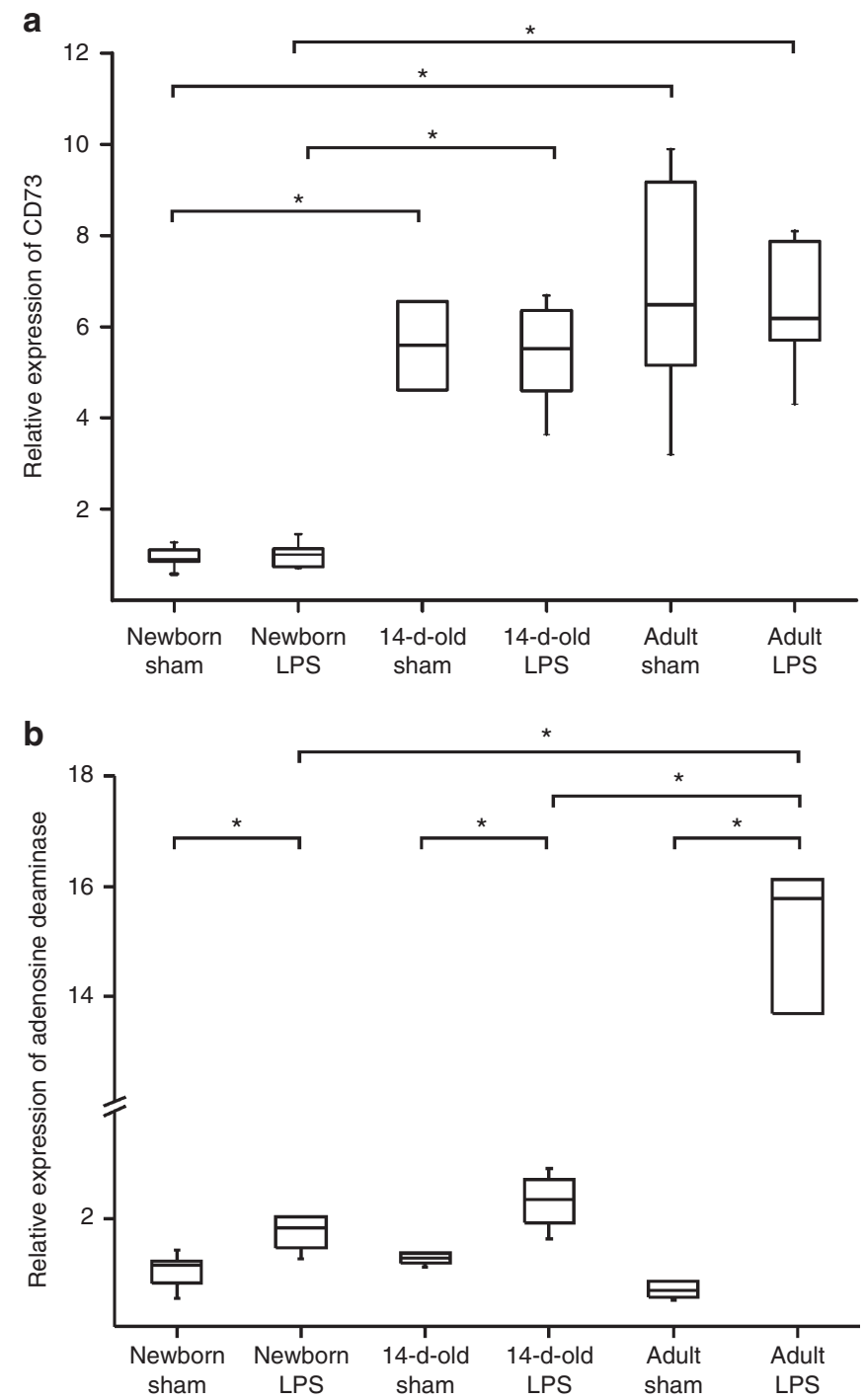

Figure 2. Expression levels of pulmonary CD73 and adenosine deaminase (ADA) in sham and lipopolysaccharide (LPS) stimulated newborn, 14-d-old, and adult mice. Relative mRNA expression levels of the enzymes CD73 (a) and ADA (b) in newborn ( $n=9$ and $n=10$ in sham and LPS groups, respectively), 14-d-old ( $n=6$ and $n=8$ in sham and LPS groups, respectively) and adult animals ( $n=5$ in both sham and LPS groups). ${ }^{*} P<0.05$.

the expression levels after the LPS insult were lower in newborn mice when compared with 14 -d-old and adult mice $(P<0.05)$. There were no detectable differences in LPS-induced expression levels of A2BR between the three age groups (Figure 3b,c).

In newborn and adult mice, the expression levels of A3R increased fourfold after the LPS injection $(P<0.05)$. In 14-d-old animals, the levels tended to be higher in the LPS group. Expression levels of A3R after the LPS injection tended to be higher in newborn than in 14-d-old mice $(P<0.05)$ (Figure 3d).

\section{The Immunohistochemistry of A1R}

Immunohistochemistry was performed to study the distribution and content of the A1R protein. A1R positivity was evident in lungs from many newborn (four out of seven animals) (Figure 4b) and some 14-d-old animals (two out of six) 
a

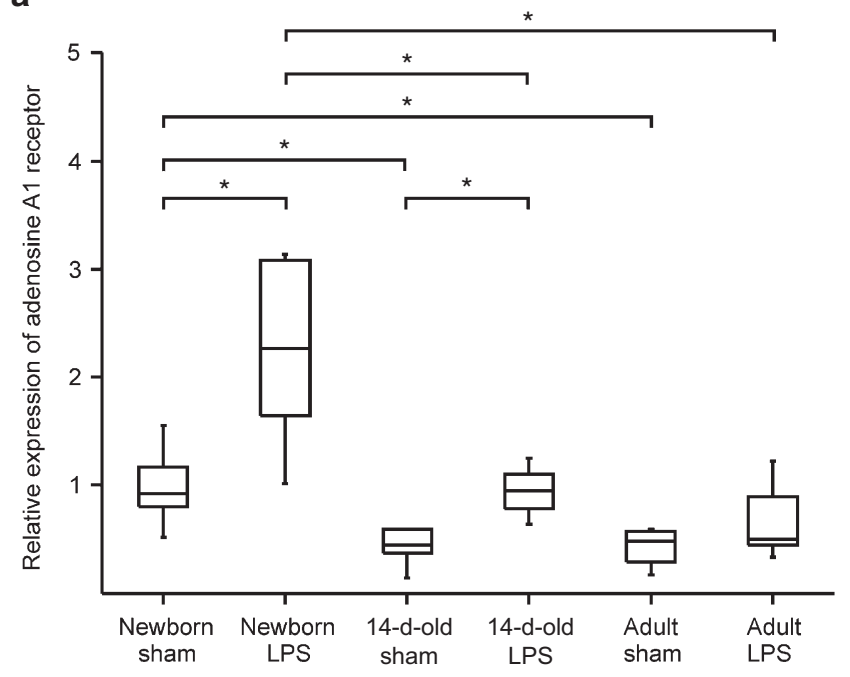

C

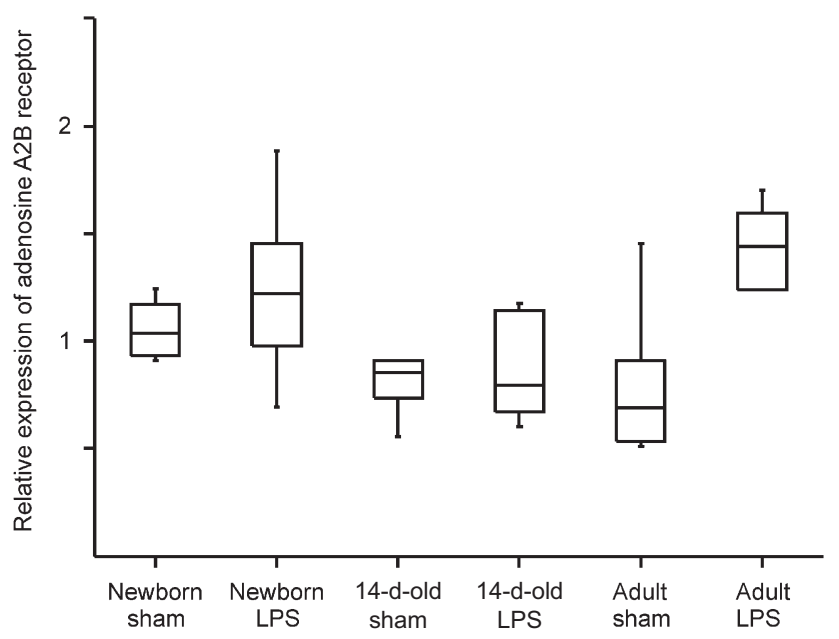

b

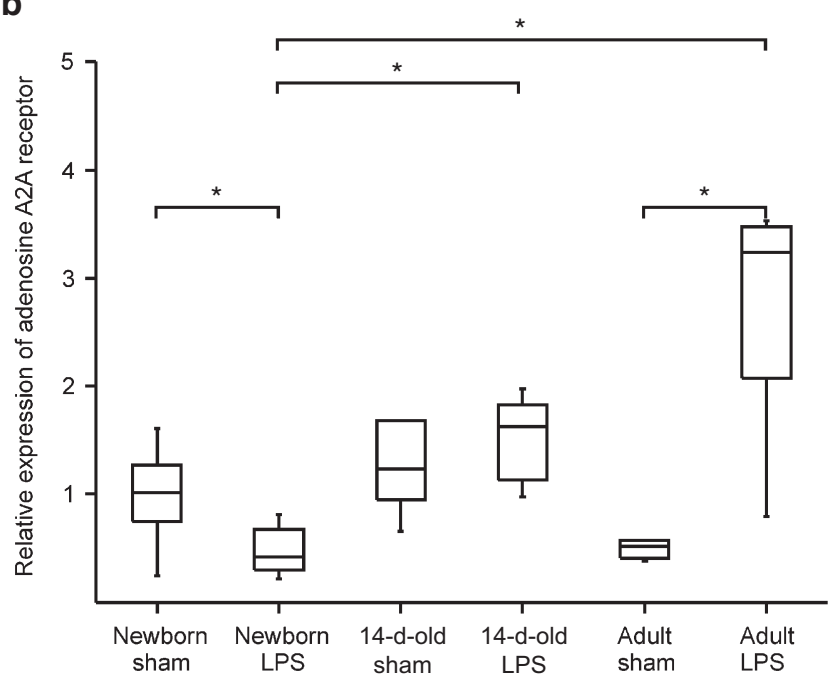

d

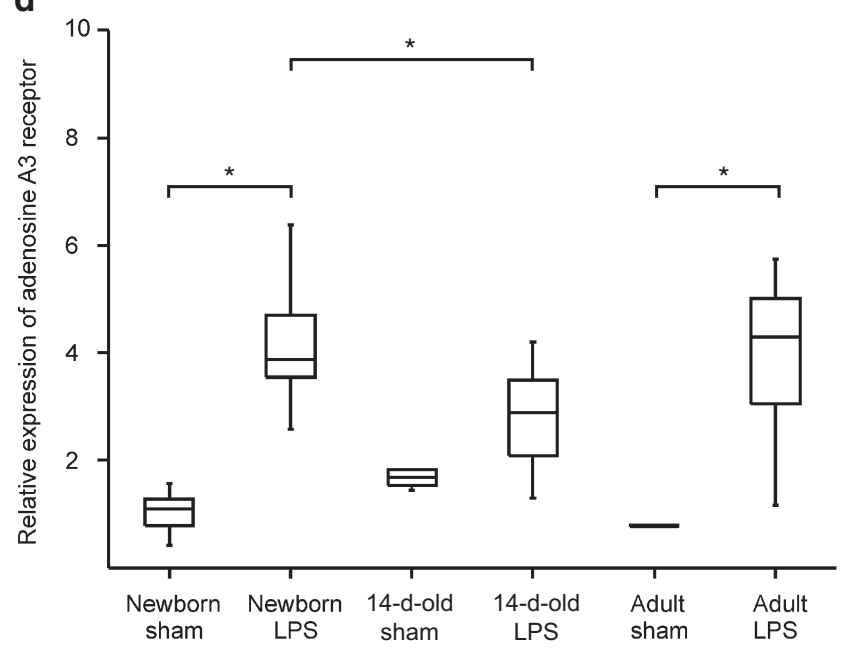

Figure 3. Expression levels of adenosine receptors in sham and lipopolysaccharide (LPS) stimulated newborn, 14-d-old, and adult mice. Relative mRNA expression levels of adenosine receptors A1, A2A, A2B, and A3 (a-d, respectively) in newborn ( $n=9$ and $n=10$ in sham and LPS groups, respectively), 14-d-old ( $n=6$ and $n=8$ in sham and LPS groups, respectively), and adult animals ( $n=5$ in both sham and LPS groups). ${ }^{*} P<0.05$.

(Figure 4d) $6 \mathrm{~h}$ after the LPS injection, whereas immunostaining was barely detectable in the lungs from newborn (two out of six) and 14-d-old (two out of six) sham animals (Figure 4a,c). The staining was detected mainly in the endothelial cells.

\section{DISCUSSION}

In the present study, we found evidence of the vulnerability of structurally immature lung tissue to a vascular inflammatory insult, suggesting that resistance to i.p. LPS develops as a function of the postnatal age. In an attempt to clarify the age-dependent increase in tolerance to an inflammatory insult, we studied the expression of both the adenosine receptors and the expression and activities of enzymes involved in adenosine metabolism, known to play a role in pulmonary immunity and the maintenance of vascular integrity $(24,27,28)$. We found that CD73 activity, protective against vascular inflammation, increased markedly soon after birth. In addition, the LPS-mediated induction of inflammatory A1R expression decreased after birth, whereas LPS-induced suppression of anti-inflammatory A2AR was abolished after birth. We propose that extracellular adenosine levels and adenosine receptors may play a role in LPS-induced toxicity.

In the present study, we demonstrate a neonatal increase in both the activity and the expression of CD73, suggesting an increase in the capacity to generate extracellular adenosine. It may be argued that newborn mice have lower capacity to produce adenosine, resulting in stronger LPS-induced inflammatory responses compared to older animals. In contrast, the expression of Toll-like receptor $4(29,30)$ and the inflammatory cytokine responses (31) increase during the perinatal development, but do not parallel the perinatal development of resistance against acute inflammatory insults.

The basal expression levels of proinflammatory A1R were higher in newborn mice and the LPS-induced increase in the expression levels was evident only in the newborn mice. A1R protein was detected in endothelial cell membranes particularly after administration of LPS. The differences seen in A1R expression between newborn and older mice may be one 

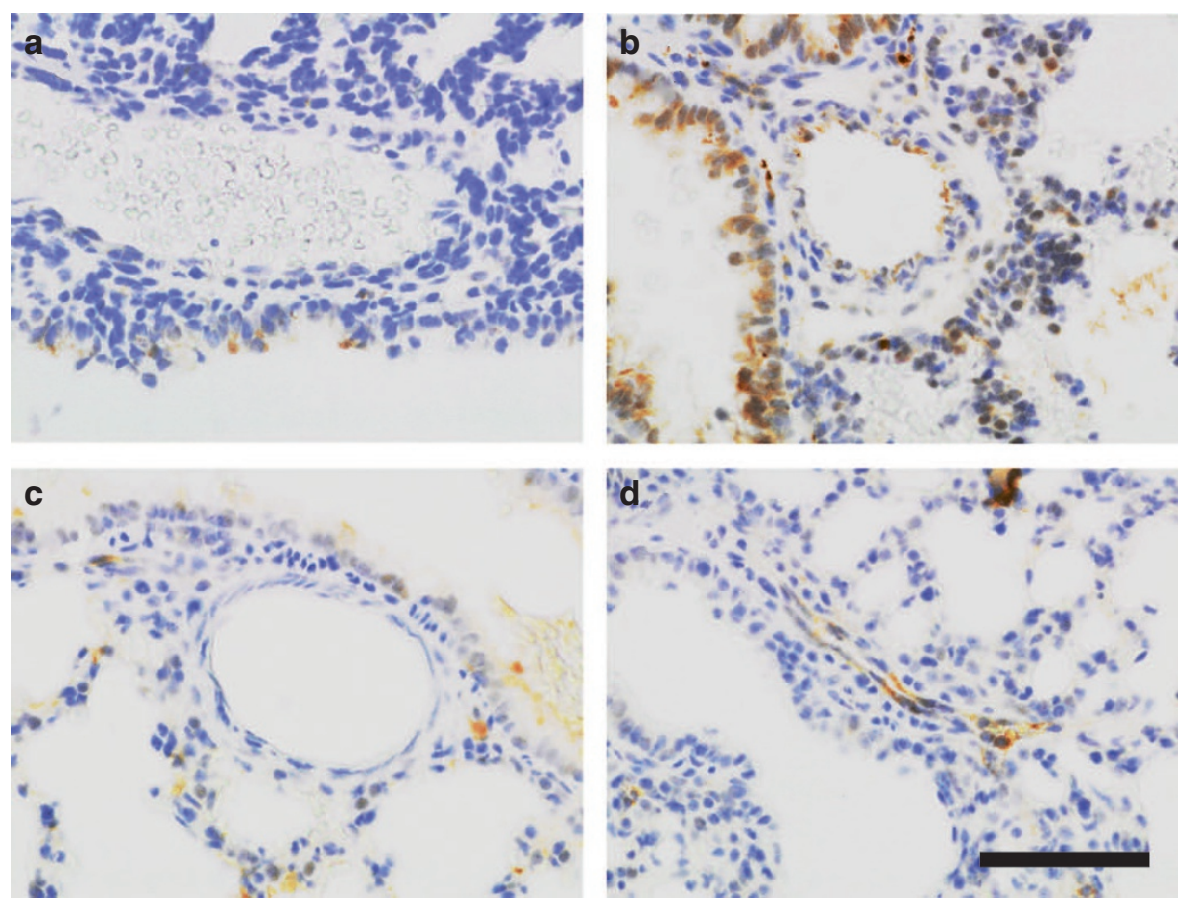

Figure 4. LPS increases adenosine receptor A1 immunostaining compared to sham mice. Immunohistochemistry staining using A1R antibody with hematoxylin-eosin counterstaining of newborn sham lungs (a), newborn lungs $6 \mathrm{~h}$ after the lipopolysaccharide (LPS) exposure (b), and 14-d-old sham lungs (c) and 14-d-old mouse lungs $6 \mathrm{~h}$ after the LPS exposure (d). Bottom right bar $=100 \mu \mathrm{m}$.

mechanism explaining the inflammatory state in the newborns. The basal expression levels of adenosine receptors A2AR, $\mathrm{A} 2 \mathrm{BR}$, and $\mathrm{A} 3 \mathrm{R}$ revealed no remarkable trends in postnatal lung. However, the expression levels in response to LPS were different between the age groups (Table 2). Most strikingly, the anti-inflammatory A2AR revealed LPS-induced suppression in newborns, whereas in adults, a significant LPS-induced increase of A2AR expression was evident. The immunohistochemical verification of these findings failed due to low quality of available commercial A2AR antibodies.

Adenosine deaminase has been considered to be an allosteric agonist for A1R, and A2AR (32) and $\mathrm{ADA}^{-/-}$mice have chronic pulmonary inflammation and fibrosis (33). This raises the possibility that interaction between ADA and A2AR may influence the inflammatory response. However, direct evidence for this is lacking. In the present study, we found no detectable increase in ADA activity within $6 \mathrm{~h}$ after i.p. LPS. However, LPS rapidly induced an increase in the expression of ADA in each age group. In adult mice, the increase was $\sim 16$-fold, compared with a 2 -fold increase in newborn mice (Figure 2b). The discrepancy between the mRNA levels and enzymatic activity of ADA may be explained by the delay between the mRNA induction and the protein synthesis. An increase in ADA without an increase in CD73 may have an additional influence on the adverse consequences of LPS in the newborn. The intriguing possibility that serum adenosine levels influence the resistance to LPS remains to be studied.

Acute lung injury induced by LPS is well documented and previous results are consistent with the present observations $(34,35)$. Within $24 \mathrm{~h}$ after i.p. administration of LPS, most newborn pups developed signs of severe respiratory distress. In contrast, the same LPS dose given to 14-d-old animals did not cause evidence
Table 2. Changes in gene expression after LPS injection

\begin{tabular}{|c|c|c|c|c|c|c|}
\hline & \multicolumn{2}{|c|}{ Newborn } & \multicolumn{2}{|c|}{ 14-d-old } & \multicolumn{2}{|c|}{ Adult } \\
\hline & Sham & LPS & Sham & LPS & Sham & LPS \\
\hline CD73 & Low & N.C. & High & N.C. & High & N.C. \\
\hline ADA & - & $\uparrow$ & - & $\uparrow$ & - & $\uparrow \uparrow$ \\
\hline$A 1 R$ & High & $\uparrow \uparrow$ & Low & $\uparrow$ & Low & N.C. \\
\hline A2AR & - & $\downarrow$ & - & N.C. & - & $\uparrow \uparrow$ \\
\hline A2BR & - & N.C. & - & N.C. & - & N.C. \\
\hline$A 3 R$ & - & $\uparrow$ & - & N.C. & - & $\uparrow$ \\
\hline
\end{tabular}

$\uparrow=$ LPS injection increased expression levels. $\uparrow \uparrow=$ The increase was significantly greater than other increase(s) in same direction. $\downarrow=$ LPS injection decreased expression levels. LPS, lipopolysaccharide; N.C., no changes.

of respiratory distress. Study of lung histology $6 \mathrm{~h}$ after LPS injection revealed a trend toward more severe lung injury in newborn compared with older mice. However, the neutrophil count in the newborn mice after LPS challenge was comparable to that in the older mice. In a study by Alvira et al. (36), the inflammatory response after i.p. LPS was milder and the adverse consequences to activation of nuclear factor- $\mathrm{\kappa B}$ were fewer in 5-d-old mice than in adults. We propose that the increase in resistance of the vascular endothelium against inflammatory injury may depend on the development of responsiveness of the adenosine receptors and enzymatic activities involved in adenosine metabolism.

In conclusion, our results show evidence that compared to adult mice, newborn mice have significantly lower expression of pulmonary anti-inflammatory adenosine receptors and significantly increased expression of proinflammatory adenosine receptors after an inflammatory insult. In addition, the expression of ADA during the inflammatory state was lower in the 
Table 3. Primer sequences for quantitative polymerase chain reaction

\begin{tabular}{|c|c|c|c|c|}
\hline Gene & Protein & Sequence $5^{\prime}-3^{\prime}$ & Final concentration ( $\mathrm{nmol} / \mathrm{l})$ & Product size (bp) \\
\hline Adora1 & $\mathrm{A} 1 \mathrm{R}$ & $\begin{array}{l}\text { F: CAA GGG AGA GAA TCC AGC AG; } \\
\text { R: ACC TCC GAG TCA AGA TCC CT }\end{array}$ & 120 & 93 \\
\hline Adora $2 b$ & $\mathrm{~A} 2 \mathrm{BR}$ & $\begin{array}{l}\text { F:TGT CCC AGT GAC CAA ACCTT; } \\
\text { R:TGC TCA CAC AGA GCT CCATC }\end{array}$ & 120 & 101 \\
\hline ADA & ADA & $\begin{array}{l}\text { F: GAT GGTTTC TGG CTT GAT GG; } \\
\text { R: ACG CAG ACC CAG AGA GCTT }\end{array}$ & 150 & 132 \\
\hline NT5E & CD73 & $\begin{array}{l}\text { F: GTC CCC CATTGA TGA GAA GA; } \\
\text { R: CAA AAG CCTTCTTCA GGG TG }\end{array}$ & 150 & 122 \\
\hline TBP & TBP & $\begin{array}{l}\text { F: GAA TAT AAT CCC AAG CGA TTT G; } \\
\text { R: CAC ACC ATTTTT CCA GAA CTG }\end{array}$ & 150 & 92 \\
\hline
\end{tabular}

TBP, TATA-box binding protein.

newborn and young animals than in adults. ADA has been shown to increase the affinity of the A2A receptor to adenosine (37). Finally, CD73, catalyzing the formation of adenosine, increased in parallel with vascular development of murine lung shortly after birth. In human, lung analogous vascular development starts preterm (38). We propose that the increasing resistance to vascular inflammatory insults may be influenced by adenosine receptors and enzymes regulating both adenosine levels and its affinity to specific receptors. The immature inflammatory responses of ADA and the adenosine receptors in preterm infants susceptible to chronic lung disease remain to be studied.

\section{METHODS}

Animals

Newborn (age $<24 \mathrm{~h}$ at the onset of the study), 1-d-old, 10-d-old, 14-d-old, and adult C57BL/6 mice from the Laboratory Animal Center of University of Oulu were used. All studies were approved by the Finnish Animal Ethics Committee.

\section{Mouse Model of i.p. LPS}

Escherichia coli LPS (serotype 0111:B4, Sigma-Aldrich, St Louis, $\mathrm{MO}$ ) or $0.9 \%$ saline carrier was injected i.p. as a single bolus using a NovoPen junior insulin injector with a NovoFine $32 \mathrm{G}$ needle (NovoNordisk A/S, Bagsvaerd, Denmark). In preliminary experiments, the mice were inspected every $2-3 \mathrm{~h}$ during the experiment for $24 \mathrm{~h}$. In cases of severe respiratory distress (cyanosis, gasping), the mice were euthanized. The dose chosen provoked respiratory failure in 50 percent of the animals in pilot studies using newborn mice (data not shown). The LPS dose was $0.5 \mu \mathrm{g} / \mathrm{g}$ for each animal. The concentration of reconstituted LPS was $0.03 \mu \mathrm{g} / \mu \mathrm{l}$.

The specimens were collected $6 \mathrm{~h}$ after the i.p. LPS or saline. Before collection, the animals were euthanized by cutting the neck vertebra. The chest was opened by a median sternotomy. Care was taken to avoid bleeding to the trachea during lung preparation. The lungs were immediately frozen in liquid nitrogen and stored at $-74{ }^{\circ} \mathrm{C}$ or fixed in $4 \%$ formaldehyde.

\section{Analysis of Expression of CD73, ADA, and Adenosine Receptors}

Total RNA from lungs was isolated using Tri-reagent (Sigma-Aldrich) according to the manufacturer's instructions. For quantitative reverse transcription polymerase chain reaction, the RNA was purified by using RNeasy Micro Kits (Qiagen Venlo, NL). cDNA was acquired from the purified mRNA with iScript cDNA Synthesis Kit (Bio-Rad Laboratories, Hercules, CA). Levels of gene expression of CD73 (NT5E), ADA, and adenosine receptors A1 (Adora1), A2A (Adora2a), $\mathrm{A} 2 \mathrm{~B}$ (Adora $2 \mathrm{~b}$ ), and A3 (Adora3) were measured by using a Bio-Rad

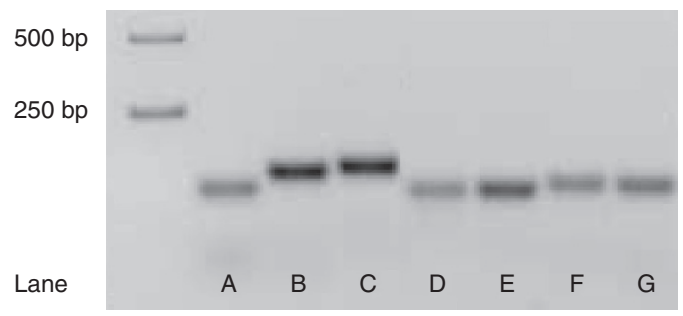

Figure 5. Gel electrophoresis of the polymerase chain reaction products. TBP, CD73, ADA, A1R, A2AR, A2BR, and A3R are in lanes a-g, respectively. $250 \mathrm{bp}$ standard was used.

Cfx-96 real-time PCR detection system (Bio-Rad Laboratories). Relative quantification was carried out with the $\Delta C_{t}$ method using the TATA-binding protein gene as a reference gene. The primers used are shown in Table 3 . The sizes of PCR products were confirmed by means of gel electrophoresis in which the $2 \%$ agarose in $1 \times$ TAE was used (Figure 5). The number of independent analyses was four to six for each individual group of specimens.

\section{Analysis of the CD73 and ADA Activities}

CD73 and ADA activities were measured in lung tissue lysates from the newborn, 1-d-old and 10-d-old mice using a thin layer chromatography method previously described by Yegutkin et al. (39). Briefly, tissue lysates $\left(20 \mu \mathrm{g}\right.$ of protein) were incubated for $60 \mathrm{~min}$ at $37^{\circ} \mathrm{C}$ in a final volume of $80 \mu \mathrm{l}$ RPMI-1640 medium containing $4 \mathrm{mmol} / \mathrm{l} \beta$-glycerophosphate and $300 \mu \mathrm{mol} / \mathrm{l}$ of either $\left[2-{ }^{3} \mathrm{H}\right] \mathrm{AMP}$ (Quotient Bioresearch, GE Healthcare, Rushden, UK) or $\left[2-{ }^{3} \mathrm{H}\right]$ adenosine (Amersham, Little Chalfont, UK) in the case of ecto- $5^{\prime}$-nucleotidase/CD73 and ADA assays, respectively. Catalytic reactions were terminated by applying aliquots of the mixture onto Alugram SIL G/UV ${ }_{254}$ sheets (Macherey-Nagel, Duren, Germany). ${ }^{3} \mathrm{H}$-labeled AMP and nucleosides were separated by TLC and quantified by scintillation $\beta$-counting.

\section{Histology and Immunohistohemistry}

Tissue samples were embedded in paraffin and cut into $2.5-\mu \mathrm{m} \mathrm{sec-}$ tions. The sections were stained with hematoxylin-eosin. Neutrophil counts were assessed in five high-power fields. In addition, alveolar congestion was graded on four-tiered systems from two tissue sections: no congestion $=0$, congestion in $<25 \%$ of the field area $=1$, in $25-49 \%$ of the field area $=2$, in $50-74 \%$ of the field area $=3$, and $75-100 \%$ of the field area $=4(40)$. The histological examiner was blinded as to which group the animal belonged to. For the immunohistochemical staining of A1R in mouse lungs, $3.5 \mu \mathrm{m}$ sections were taken from formalin-fixed paraffin-embedded tissue and the rabbit polyclonal anti-ADORA1 antibody from Abcam (ab82477, Abcam, Cambridge, MA) was used. 


\section{Statistical Analysis}

One-way ANOVA with two-sample $t$-tests as post hoc tests were used for comparison of means. Bonferroni corrections were used for multiple comparisons. The level of significance was $P<0.05$. OriginPro v.9.0.0 software (OriginLab, Northampton, MA) was used for statistical analysis.

\section{ACKNOWLEDGMENTS}

We thank Maarit Haarala, Riitta Vuento, Sari Mäki, and Erja Tomperi for technical assistance.

\section{STATEMENT OF FINANCIAL SUPPORT}

This study was supported by the Alma and K. A. Snellman Foundation, Oulu, Finland; the Foundation for Pediatric Research, Helsinki, Finland; Sigrid Juselius Foundation, Helsinki, Finland; and the Academy of Finland, Helsinki, Finland.

Disclosure: The authors have no conflict of interest to disclose.

\section{REFERENCES}

1. Schepp CP, Reutershan J. Bench-to-bedside review: adenosine receptorspromising targets in acute lung injury? Crit Care 2008;12:226.

2. Yegutkin GG. Nucleotide- and nucleoside-converting ectoenzymes: Important modulators of purinergic signalling cascade. Biochim Biophys Acta 2008;1783:673-94.

3. Zimmermann $\mathrm{H}$, Zebisch $\mathrm{M}$, Sträter N. Cellular function and molecular structure of ecto-nucleotidases. Purinergic Signal 2012;8:437-502.

4. Kiss J, Yegutkin GG, Koskinen K, Savunen T, Jalkanen S, Salmi M. IFNbeta protects from vascular leakage via up-regulation of CD73. Eur J Immunol 2007;37:3334-8.

5. Bellingan G, Maksimow M, Howell DC, et al. The effect of intravenous interferon-beta-1a (FP-1201) on lung CD73 expression and on acute respiratory distress syndrome mortality: an open-label study. Lancet Respir Med 2014;2:98-107.

6. Karmouty-Quintana H, Xia Y, Blackburn MR. Adenosine signaling during acute and chronic disease states. J Mol Med (Berl) 2013;91:173-81.

7. He X, Hu JL, Li J, et al. A feedback loop in PPAR $\gamma$-adenosine A2A receptor signaling inhibits inflammation and attenuates lung damages in a mouse model of LPS-induced acute lung injury. Cell Signal 2013;25:1913-23.

8. Li J, Zhao L, He X, Zeng YJ, Dai SS. Sinomenine protects against lipopolysaccharide-induced acute lung injury in mice via adenosine $\mathrm{A}(2 \mathrm{~A})$ receptor signaling. PLoS One 2013;8:e59257.

9. Wagner R, Ngamsri KC, Stark S, Vollmer I, Reutershan J. Adenosine receptor A3 is a critical mediator in LPS-induced pulmonary inflammation. Am J Physiol Lung Cell Mol Physiol 2010;299:L502-12.

10. Ondrackova P, Kovaru H, Kovaru F, Leva L, Faldyna M. Adenosine modulates LPS-induced cytokine production in porcine monocytes. Cytokine 2013;61:953-61.

11. Elson G, Eisenberg M, Garg C, et al. Induction of murine adenosine A(2A) receptor expression by LPS: analysis of the 5' upstream promoter. Genes Immun 2013;14:147-53.

12. Folkesson HG, Kuzenko SR, Lipson DA, Matthay MA, Simmons MA. The adenosine 2A receptor agonist GW328267C improves lung function after acute lung injury in rats. Am J Physiol Lung Cell Mol Physiol 2012;303:L259-71.

13. Pettengill M, Robson S, Tresenriter M, et al. Soluble ecto-5'-nucleotidase (5'-NT), alkaline phosphatase, and adenosine deaminase (ADA1) activities in neonatal blood favor elevated extracellular adenosine. J Biol Chem 2013;288:27315-26.

14. Canpolat FE, Yurdakök M, Korkmaz A, Yiğit S, Tekinalp G. Adenosine deaminase levels in premature infants with respiratory distress syndrome and bronchopulmonary dysplasia. J Matern Fetal Neonatal Med 2011;24:703-7.

15. Levy O, Coughlin M, Cronstein BN, Roy RM, Desai A, Wessels MR. The adenosine system selectively inhibits TLR-mediated TNF-alpha production in the human newborn. J Immunol 2006;177:1956-66.

16. Chavez-Valdez R, Wills-Karp M, Ahlawat R, Cristofalo EA, Nathan A, Gauda EB. Caffeine modulates TNF-alpha production by cord blood monocytes: the role of adenosine receptors. Pediatr Res 2009;65:203-8.
17. Chavez Valdez R, Ahlawat R, Wills-Karp M, Nathan A, Ezell T, Gauda EB. Correlation between serum caffeine levels and changes in cytokine profile in a cohort of preterm infants. J Pediatr 2011;158:57-64, 64.e1.

18. Jobe AH. Effects of chorioamnionitis on the fetal lung. Clin Perinatol 2012;39:441-57.

19. Speer CP. Chorioamnionitis, postnatal factors and proinflammatory response in the pathogenetic sequence of bronchopulmonary dysplasia. Neonatology 2009;95:353-61.

20. Yerkovich ST, Wikström ME, Suriyaarachchi D, Prescott SL, Upham JW, Holt PG. Postnatal development of monocyte cytokine responses to bacterial lipopolysaccharide. Pediatr Res 2007;62:547-52.

21. Kunzmann S, Collins JJ, Kuypers E, Kramer BW. Thrown off balance: the effect of antenatal inflammation on the developing lung and immune system. Am J Obstet Gynecol 2013;208:429-37.

22. Adams-Chapman I. Long-term impact of infection on the preterm neonate. Semin Perinatol 2012;36:462-70.

23. Reiss LK, Uhlig U, Uhlig S. Models and mechanisms of acute lung injury caused by direct insults. Eur J Cell Biol 2012;91:590-601.

24. Ålgars A, Karikoski M, Yegutkin GG, et al. Different role of CD73 in leukocyte trafficking via blood and lymph vessels. Blood 2011;117:4387-93.

25. Stevens T. Functional and molecular heterogeneity of pulmonary endothelial cells. Proc Am Thorac Soc 2011;8:453-7.

26. Zhang Q, Coveney AP, Yu S, et al. Inefficient antimicrobial functions of innate phagocytes render infant mice more susceptible to bacterial infection. Eur J Immunol 2013;43:1322-32.

27. Petrovic-Djergovic D, Hyman MC, Ray JJ, et al. Tissue-resident ecto-5 nucleotidase (CD73) regulates leukocyte trafficking in the ischemic brain. J Immunol 2012;188:2387-98.

28. Reutershan J, Vollmer I, Stark S, Wagner R, Ngamsri KC, Eltzschig HK. Adenosine and inflammation: $\mathrm{CD} 39$ and $\mathrm{CD} 73$ are critical mediators in LPS-induced PMN trafficking into the lungs. FASEB J 2009;23:473-82.

29. Shen CM, Lin SC, Niu DM, Kou YR. Development of monocyte Toll-like receptor 2 and Toll-like receptor 4 in preterm newborns during the first few months of life. Pediatr Res 2013;73:685-91.

30. Harju K, Glumoff V, Hallman M. Ontogeny of Toll-like receptors Tlr2 and Tlr4 in mice. Pediatr Res 2001;49:81-3.

31. Harju K, Ojaniemi M, Rounioja S, et al. Expression of toll-like receptor 4 and endotoxin responsiveness in mice during perinatal period. Pediatr Res 2005;57(5 Pt 1):644-8.

32. Gracia E, Cortés A, Meana JJ, et al. Human adenosine deaminase as an allosteric modulator of human A(1) adenosine receptor: abolishment of negative cooperativity for $[\mathrm{H}]^{\circ}$-pia binding to the caudate nucleus. J Neurochem 2008;107:161-70.

33. Chunn JL, Mohsenin A, Young HW, et al. Partially adenosine deaminasedeficient mice develop pulmonary fibrosis in association with adenosine elevations. Am J Physiol Lung Cell Mol Physiol 2006;290:L579-87.

34. Rose CE Jr, Juliano CA, Tracey DE, Yoshimura T, Fu SM. Role of interleukin-1 in endotoxin-induced lung injury in the rat. Am J Respir Cell Mol Biol 1994;10:214-21.

35. Altınsoy C, Tuzun F, Duman N, et al. Effect of induced hypothermia on lipopolysaccharide-induced lung injury in neonatal rats. J Matern Fetal Neonatal Med 2014;27:421-9.

36. Alvira CM, Abate A, Yang G, Dennery PA, Rabinovitch M. Nuclear factor-kappaB activation in neonatal mouse lung protects against lipopolysaccharide-induced inflammation. Am J Respir Crit Care Med 2007;175:805-15.

37. Gracia E, Pérez-Capote K, Moreno E, et al. A2A adenosine receptor ligand binding and signalling is allosterically modulated by adenosine deaminase. Biochem J 2011;435:701-9.

38. Warburton D, El-Hashash A, Carraro G, et al. Lung organogenesis. Curr Top Dev Biol 2010;90:73-158.

39. Yegutkin GG, Samburski SS, Jalkanen S. Soluble purine-converting enzymes circulate in human blood and regulate extracellular ATP level via counteracting pyrophosphatase and phosphotransfer reactions. FASEB J 2003; 17:1328-30.

40. Su X, Wang L, Song Y, Bai C. Inhibition of inflammatory responses by ambroxol, a mucolytic agent, in a murine model of acute lung injury induced by lipopolysaccharide. Intensive Care Med 2004;30:133-40. 